\title{
Intestinal Parasitosis among School Going Children in Bhaktapur, Nepal
}

\author{
Sabnum Shrestha ${ }^{1 *}$, Sulochana Laluwa ${ }^{1}$, Bimala Ranamagar ${ }^{1}$, Pramila Thapa ${ }^{1}$, Manoj Pradhan $^{2}$, Nabaraj \\ Adhikari $^{1}$, Upendra Thapa Shrestha ${ }^{1}$ \\ 1 Department of Microbiology, Kantipur College of Medical Sciences, Tribhuvan University, Nepal \\ 2 Department of Microbiology, Nepalese Army Institute of Health Sciences, Nepal
}

\begin{abstract}
Background: Intestinal parasites continue to be an important cause of public health problems in the world, particularly among children living in developing countries. The study was aimed to assess the load of intestinal parasites among school going children of Bhaktapur district of Nepal.
\end{abstract}

Methods: A total of 184 stool samples were collected from school children of Bhaktapur district between the age group 3-14 years. The stools collected were examined by direct microscopy and confirmed by concentration methods (formal ether sedimentation technique).

\section{Results:}

Prevalence of intestinal parasites among the children was found to be $42.9 \%$ (79/184). Giardia lamblia was the most predominant parasite, showing the incidence of $35.7 \%$, followed by Taenia spp $22.6 \%$ and Blastocystis hominis $14.3 \%$.

Conclusions: High parasitic infection in this study area may be due to lack of pure drinking water, lack of health education, unhygienic condition and presence of livestock near home, which is a major public health threat among school going children resulting serious illness.

Keywords: Parasites, Stool samples, microscopy, ether sedimentation technique

\section{BACKGROUND}

Intestinal parasitic infection is most prevalent throughout the world, particularly in developing nations. Approximately, 3.5 billion people are infected with parasitic infection and around 450 billion people are ill due to these infections $[1,2]$. Nepal is a landlocked, impoverished and least developed country located in South Asia where $70 \%$ of public health problems are due to infectious disease $[3,4]$. Intestinal parasitosis is one of the major causes of morbidity and mortality in Nepal [5].

*Correspondence: Sabnum Shrestha ${ }^{1}$ Department of Microbiology, Kantipur College of Medical Sciences, Kathmandu, Nepal

E-mail: sabnum0602@gmail.com
The study conducted by Shrestha et al, 2013 in Bhaktapur district, Nepal in 2011 showed 27.67\% prevalence while Chandrashekhar et al, 2005 showed prevalence of $21.3 \%$ of intestinal parasites in school-going children $[6,2]$. High prevalence is attributed to poverty, lack of awareness, failure to practice proper hand washing after defecation, unsafe drinking water and use of improper toilets [7].

The common intestinal parasites reported from Nepalese children are Giardia lamblia, Ascaris lumbricoides, Trichuris trichiura and Hookworm. The agents spread faeco-orally through contaminated sources. Although people of all ages are infected with this organism, children 
are more often infected due to compromised sanitary habits $[8,9]$.

Thus, the present study was carried out to find the present situation of the parasitic infections among school going children of Bhaktapur district of Nepal.

\section{METHODOLOGY}

A total of 184 children from Bhaktapur district were taken as study population and fecal samples were collected during April - May, 2013.To collect stools, children were given sterile containers the day before sampling along with comprehensive instructions. A questionnaire on age, sex, and hygienic practices were used for analysis. Stools were collected and transported to the Laboratory of Kantipur College of Medical Science for further processing. Stool specimens were concentrated by formal-ether sedimentation technique. The concentrated stools were further processed by conventional iodine and saline wet mounting [10]. Data were entered into Microsoft excel and stratified according to sex using SPSS software (version 16.0). The Chi-square test was performed with a significance level of $<0.05$ for statistical analysis.

\section{RESULTS}

Stool samples from 184 students of age group between 2-17 years old were examined and overall rate of intestinal parasitosis were found to be $42.9 \%$ (Table 1). Giardia lamblia was found to be the most predominant parasite followed by Taenia spp, Blastocystis hominis and Trichuris trichiura (Table 3). The rate of parasitic infection in boys (45.3\%) was slightly higher as compared to girls $(40.4 \%)$. The maximum intestinal parasitic infection (43\%) was found in age group between 6-10 years (Fig 1). Protozoan infestation rate was high (59.5\%) as compared to helminthic (40.5\%).

Nine species of parasites, five species of protozoa and four species of helminthes were detected. Giardia lamblia was the most predominant parasite (35.7\%) amongst all isolates. Among the helminths, Taenia sp. (22.6\%), Trichuris trichiura $(8.3 \%)$ and Ascaris lumbricoides (7.1\%) accounted for the most prevalent ones. Similarly, of the protozoan parasites, Giardia lamblia (35.7\%), Blastocystis hominis (14.3\%), and Cyclospora (4.3\%) were the most frequent organisms (Table 3). While $89.8 \%$ of the children had single parasitic infection, $10.1 \%$ had mixed parasitic infection (Table 4).

A higher rate of infection was seen among the school children who had live stocks reared at home (71\%) and who drank untreated water (65.8\%) (Table 2).

Table 1: Prevalence of intestinal parasites among boys and girls of school in Bhaktapur

\begin{tabular}{|c|c|c|c|c|}
\hline Sex & Total No. & Positive No. & $\%$ & p-value \\
\cline { 1 - 4 } Boys (M) & 95 & 43 & 45.3 & \multirow{2}{*}{$>0.05$} \\
\cline { 1 - 4 } Girls (F) & 89 & 36 & 40.4 & \\
\hline Total & 184 & 79 & 42.9 & \\
\hline
\end{tabular}

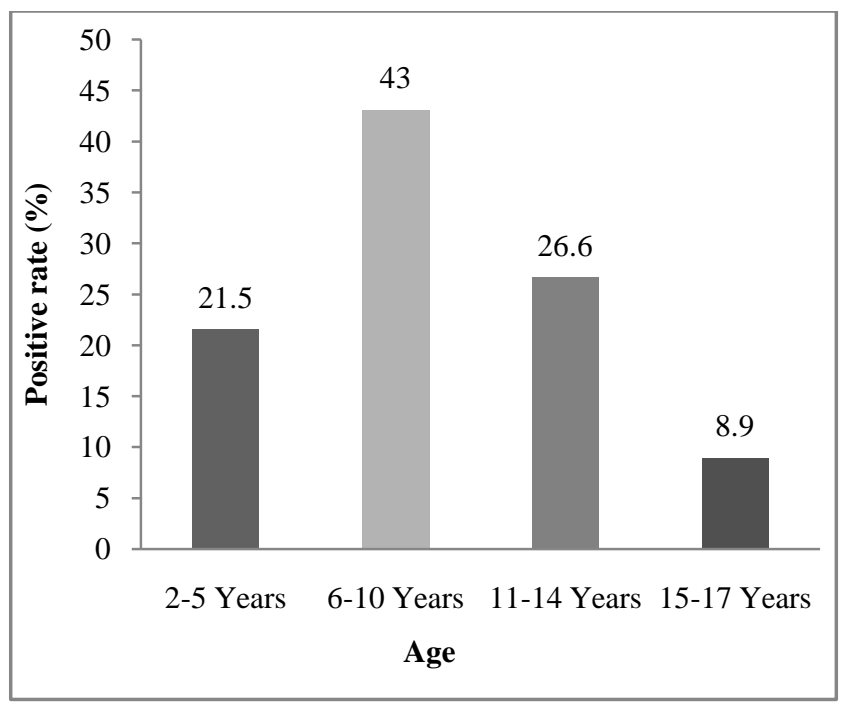

Fig 1: Prevalence of intestinal parasites among different age-groups. 
Table 2: Possible Risk Factors

\begin{tabular}{|c|c|c|}
\hline Variables & Frequency & $\%$ \\
\hline \multicolumn{3}{|l|}{ Treatment of water } \\
\hline $\begin{array}{r}\text { Boiling } \\
\text { Filtration } \\
\text { Untreated }\end{array}$ & $\begin{array}{l}6 \\
21 \\
52\end{array}$ & $\begin{array}{l}7.6 \\
26.6 \\
65.8\end{array}$ \\
\hline \multicolumn{3}{|l|}{ Live stocks present at home } \\
\hline $\begin{array}{l}\text { Positive parasitic infection } \\
\text { Negative parasitic infection }\end{array}$ & $\begin{array}{l}56 \\
23\end{array}$ & $\begin{array}{l}71 \\
29\end{array}$ \\
\hline
\end{tabular}

Table 3: Frequency of intestinal parasites

\begin{tabular}{r|cc|}
\multicolumn{1}{c|}{ Types of Parasites } & Total number & \% \\
\hline Protozoa & 50 & 59.5 \\
Giardia lamblia & 30 & 35.7 \\
Blastocystis hominis & 12 & 14.3 \\
Cyclospora & 4 & 4.8 \\
E. histolytica & 3 & 3.6 \\
Balantidium coli & 1 & 1.2 \\
Helminths & 34 & 40.5 \\
Trichuris trichiura & 19 & 22.6 \\
Ascaris lumbricoides & 7 & 8.3 \\
Hymenolepsis nana & 6 & 7.1 \\
Total & 2 & 2.4 \\
\cline { 2 - 3 } & $\mathbf{8 4}$ & $\mathbf{1 0 0}$ \\
\hline
\end{tabular}

Table 4: Pattern of intestinal parasitic infections

\begin{tabular}{|c|c|c|}
\hline Types of infection & Total no. & $\%$ \\
\hline Single parasite & 71 & 89.8 \\
\hline Protozoa & 46 & 64.7 \\
\hline Helminths & 25 & 35.2 \\
\hline Multiple parasites & 8 & 10.1 \\
\hline Protozoa & 4 & 0.5 \\
\hline Helminths & 2 & 0.25 \\
\hline Protozoa+ Helminths & 2 & 0.25 \\
\hline Total & 79 & 100 \\
\hline
\end{tabular}

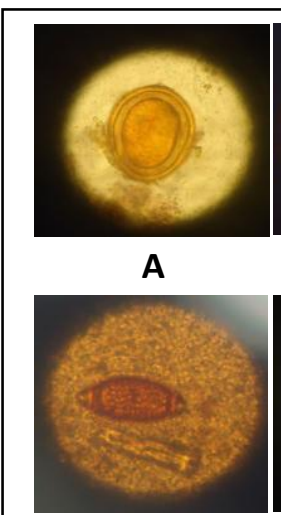

D

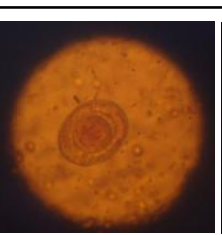

B

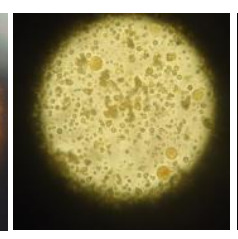

E

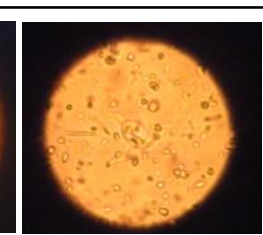

C

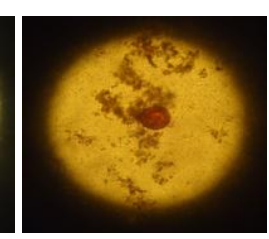

$\mathbf{F}$
Fig 2: Microscopy images of Intestinal parasites A: Ascaris lumbricoides, B: Hymenolepsis nana, C: Giardia lamblia, D: Trichuris trichiura

E: Blastocystis hominis, F: Taenia spp

\section{DISCUSSION}

Intestinal parasitosis is one of the major causes of death amongst people especially in school going children[11-13]. In the present study, the rate of intestinal parasitosis among school going children in Bhaktapur district was 42.9\%. However, similar study carried out in Lalitpur district conducted by Tandukar et al, in 2013 [14], the prevalence of intestinal parasitosis in school going children of was only about $16.7 \%$, suggesting that differences in time and place of the study, socioeconomic conditions, cultural practices, supply of drinking water and presence of live stocks at home can bring vast differences in the prevalence of parasitic infections.

Although intestinal parasitic infection is gender independent, higher infection rate in boys over girls was seen in the present study which was statistically insignificant $(\mathrm{P}>0.05)[15,16]$. It might be related to personal hygiene. Nowadays, most of the children, especially boys, stay in hostel, where they are encouraged to improve their personal hygiene, most specifically hand washing with soap water before meal $[7,17]$. 
Protozoan parasites were found more common $(59.5 \%)$ than the helminthic parasites $(40.5 \%)$ in the current study. It is attributed to periodic anti-helminthic drug administration program in the school children, which could possibly explain the lower prevalence of helminthic infections observed in our study.

Protozoans are dominating the helminthic parasites, which concords with the previous findings from Nepal [18, 19]. Among protozoan parasites, Giardia lamblia is the most common flagellate of the intestinal tract, causing Giardiasis in humans, which spreads faeco-orally through contaminated sources such as untreated drinking water. In our study, most frequently seen parasite was Giardia lamblia followed by Taenia spp and Blastocystis hominis. School-age children are particularly susceptible to parasitosis, often carrying higher burdens of parasites than adults [20]. This can be explained by the poor sanitary conditions and frequent exposure to the contaminated environment. In addition, they are more fascinated towards street food and drinks, which may be an important predisposing factor $[7,21]$.

High prevalence rate $(43 \%)$ of intestinal parasitosis was found in children aged 6-10 years, the findings being similar to the observation of Rashid et al. [22]. It was also in agreement with the study done by Poudyal et al [23]. School aged children acquire infection may be due to their inadequate knowledge towards the personal hygiene and their involvement in different recreational activities in the polluted environment.

The rate of infection was higher $(29.4 \%)$ in children using unboiled (direct tap) water for drinking purpose whereas lower rate $(9.0 \%)$ was found in children using boiled water for drinking [Table 2].This pattern of infection has also been reported by Wani et al. from India $[14,24]$. The reason is that, boiling of water for drinking purposes kills the microorganisms and prevents transmission of infection. Thus, poor hygiene practices associated with type of water may be probable risk factor for increased parasitic infection among children.

\section{CONCLUSION}

Intestinal parasitic infection is serious public health problem in Nepal. This study reveals that intestinal parasites are copious among school children of Bhaktapur district of Nepal. This situation highly suggest immediate need of control measures, including treatment of infected individuals, improvement of sanitation practices, and provision of safe drinking water. Furthermore, impoverishment, lack of awareness, failure to practice proper hand washing after defecation, unsafe drinking water are some of the risk factors associated with this study, as the reason of parasitic infections. Proper health education should be given to children and their parents concerning disease transmission, personal hygiene and safe drinking water, so that the infection rate can be controlled.

\section{COMPETING INTERESTS}

The authors declare that they have no competing interests concerning the work reported in this paper.

\section{CONTRIBUTIONS}

SS, SL, BRM participated in the sample collection. SS, SL, BRM carried out the different laboratory tests in the study. SS, SL, BRM performed the statistical analysis. SS and PT conceived the design of the study and guided to draft the manuscript. NA and UTS supervised the project. MP corrected the language of manuscript. All authors read and approved the final draft of the manuscript.

\section{ETHICAL CONSIDERATION}

This study was approved by Institutional Review Committee of Kantipur College of Medical Science, Kathmandu. Informed verbal agreement was taken from Patients. The intent of the study was to assess the load of 
intestinal parasites among school going children of Bhaktapur district of Nepal.

\section{ACKNOWLEDGEMENTS}

The authors are deeply indebted to the school children and their parents participating in this study. We are also thankful to Kantipur College of Medical Science, Kathmandu for providing the research platform.

\section{REFERENCES}

1. WHO: World Health Report 1997- Conquering Suffering Enriching Humanity. Geneva: World Health Organization; 1997. Available from: http://www.who.int/whr/1997/en/whr97_en.pdf

2. Chandrashekhar TS, Joshi HS, Gurung M, Subba SH, Rana MS, Shivananda PG. Prevalence and distribution of intestinal parasitic infestations among school children in Kaski District, Western Nepal. Journal of Biomedical Science. 2005; 4:78-82.

3. Rai SK, Matsumura $\mathrm{T}$, Ono $\mathrm{K}$, et al. Intestinal parasitoses in an" unknown disease outbreak" hit rural area in western Nepal. Nepal Med College J 2001; 3: 69-73.

4. Rai SK, Hirai K, Abe A, Ishiyama S, Rai G, Ono K. Intestinal parasitoses among school children in a rural hilly area of the Dhading district, Nepal. Nepal Med College J 2002; 4: 54-8.

5. Rai SK. Parasitic Diseases in Nepal. In: Asian Parasitology Vol. 1: Food-borne Helminthiasis in Asia; Editor-in-chief:Yano A. Editors: Arizona N, Chai J-Y, Nawa Y, Takahashi Y. Federation of Asian Parasitology, Japan 2004; 305-18.

6. Shrestha R and Maharjan M. Prevalence of intestinal helminth parasites among school-children of Bhaktapur district, Nepal. Central Department of Zoology, Tribhuvan University, Kirtipur, Kathmandu, Nepal. Nepalese Journal of Zoology 2013; 1:1-9.
7. Gyawali N, Amatya R, Nepal HR. Intestinal Parasitosis in school going children of Dharan Municipality, Nepal Tropical Gastroenterology 2009; 30(3):145-47

8. Saksirisampant W, N Uchprayoon S, Wiwanitkit V, Yenthakam S, Ampavasiri A: Intestinal parasitic infestations among children in an orphanage in PathumThani province. J Med Assoc Thai 2003; 86: 263-70.

9. Das Rabindranath, Pradipta Swain Kumar, Biswas R. Prevalence of intestinal parasites $\&$ itsassociation with sociodemographic, environmental \& behavioral factors in children in Pokhara valley, Nepal. Afr J Cln Exper Microbiol 2006; 7(2):106-11

10. WHO Regional Office for South East Asia. Guidelines on Standard Operating Procedure for Microbiology 2006. [Cited 2011 Aug 7]; Available from: http://www.searo.who.int/en/Section10/Section17/ Section53/Section482_1804.htm.

11. Yong TS, Sim S, Lee J, Ohrr H, Kim MH, Kim H: A small scale survey onstatus of intestinal parasite infection in rural village in Nepal. Korean J Parasitol 2000; 38:275-77

12. Pokhrel D, Viraraghavan T: Diarrhoeal diseases in Nepal vis-à-vis water supply and sanitation status. J Water Health 2004; 2:71-81.

13. Sharma BK, Rai SK, Rai DR, Choudhary DR: Prevalence of intestinal parasitic infestation in school children in the northeastern part of Kathmandu Valley, Nepal. Southeast Asian J Trop Med Public Health 2004; 35:501-505.

14. Tandukar S, Ansari S, Adhikari N, Shrestha A, Gautam J, Sharma B, Rajbhandari D, GautamS, Nepal HP, Sherchand JB. Intestinal parasitosis in school children of Lalitpur district of Nepal. BMC Research Notes 2013; 6:449. 
15. Taheri F, Namakin K, ZarbanA, Shantzadesh G. Intestinal parasitic infection among school children in south khorasan province, Iran. J Res Health Sci 2011; 11: $45-50$.

16. Rai K, Sherchand JB, Bhatta DR. Study of enteropathogens and its predisposing factors in gastroenteritis suspected children attending Kanti children Hospital, Kathmandu, Nepal. J Nepal Assoc Med Lab Sci 2004; 6: 48-53.

17. Khanal LK, Choudhury DR, Rai SK, Sapkota J, Barakoti A, Amatya R and Hada S. Prevalence of intestinal worm infestations among school children in Kathmandu, Nepal Department of Microbiology, Nepal Medical College, Jorpati, Kathmandu, Nepal, Nepal Med Coll J 2011; 13(4): 272-274

18. Sherchand JB, Larsson S, Shrestha MP: Intestinal parasites in children and adults with and without abdominal discomfort frrm the Kathmandu area of Nepal. Trop Gastroenterol 1996; 17:15-22.

19. Magar DT, Rai SK, Lekhak B, Rai KR. Study of parasitic infection among children of SukumbasiBasti in Kathmandu valley. Nepal Med Coll J. 2011; 13(1):7-10.

20. Cook DM, Swanson RC, Eggett DL, Booth GM: A Retrospective Analysis of Prevalence of Gastrointestinal Parasites among School Children in thePalajunoj Valley of Guatemala. J Health PopulNutr 2009; $27(1): 31-40$.

21. Khadka KS, Kaphle HP, Gurung K, Sigdel M: Study of intestinal parasitosis among school going children in Pokhara, Nepal. J Health Allied Sci 2013; 3(1):4750.

22. Rashid MK, Joshi MU, Joshi HS, Fatemi K. Prevalence of Intestinal Parasites among School Going Children In Bareilly District. NJIRM 2011; 2(1).
23. Poudyal AK, Jimba M, Silwal M, Silwal RC. Targeting newly enrolled low age school going children for control if intestinal helminthes infection in rural Nepal. Trop Doct. 2006; 36(1): 16-19.

24. Wani SA, Ahmad F, Zargar SA, Ahmad Z, Ahmad P, Tak H: Prevalence of intestinal parasites and associated risk factors among school children in Srinagar City, Kashmir, India. J Parasitol 2007; 93(6): $1541-43$.

\section{Article History:}

Received: 10 November, 2015

Accepted: 20 January, 2016

Published online: 15 February, 2016

\section{For Citation:}

Shrestha et al.: Intestinal parasitosis among school going children in Bhaktapur, Nepal. International Journal of Medicine \& Biomedical sciences. 2016; 1(2):1-6 